\title{
"Feeding a child slowly:" a responsive feeding behavior component likely to reduce stunting: Population-based observations from rural Zambia
}

\author{
Raider H. Mugode, Thandi Puoane, Charles Michelo \& Nelia P. Steyn
}

\begin{abstract}
Zambia has a very high prevalence of stunting (40\%). Child feeding behaviors such as "feeding the child slowly" are now receiving attention in addressing child undernutrition, particularly stunting. A study was undertaken in two rural areas of Zambia and mothers of 295 children 6-24 months old were questioned about their feeding behaviors including "feeding a child slowly." The study found reduced stunting among children older than one year who were fed slowly, had been dewormed, and consumed thicker (more energy-dense) foods. It is recommended that these feeding practices should be incorporated in health promotion interventions to reduce the burden of malnutrition.
\end{abstract}

\section{Introduction}

Globally, $25 \%$ of the children are stunted, $15 \%$ underweight, and $8 \%$ wasted. ${ }^{1}$ In subSaharan Africa, 40\% were stunted and 21\% were underweight in 2011. ${ }^{2}$ In Zambia, in $2014,40 \%$ children were stunted and $15 \%$ were underweight. ${ }^{3}$ Malnutrition is an indirect cause of child mortality and is attributed to about $35 \%$ of child deaths globally. ${ }^{4}$ Numerous consequences of undernutrition have been documented, including late school entry, poor educational attainment, early school dropout, high morbidity and mortality, economic losses due to decreased work ability, ${ }^{5}$ poor reproductive outcomes in terms of fetal death, low birth weight, obstructed labor, and increased risk of chronic diseases in adulthood. ${ }^{4,6}$

Feeding behaviors have been recognized as being key to infant and child survival, in addition to focusing on food intake and disease control. ${ }^{7}$ One such behavior is feeding the child slowly, a component of responsive feeding behavior. Responsive feeding entails an active way to motivate infants and children to eat by means of interactive behaviors between the mother/caregiver and the child. ${ }^{8}$ These include assisting the infant or child to eat; feeding with love, slowly and with patience; experimenting with different foods; and minimizing distractions during meals. ${ }^{9,10}$ Responsive feeding has long been recognized as a key element in determining child nutritional status. Responsive feeding encompasses the behavior of both the mother 
and the child being able to respond to each other during feeding. ${ }^{11}$ While the role of the mother is to provide quality and appropriate activities in a positive and supportive environment, including speed of feeding, ${ }^{12}$ the child should be allowed to feed slowly or at its own pace. Similarly, controlling feeding behaviors such as forcing the child to eat, unattended self-feeding, and dietary restrictions can lead to less food intake, placing the child at risk of malnutrition. ${ }^{11-16}$

Responsive feeding is among the child-care practices that are known to increase child food intake and reduce the risk of disease. ${ }^{8,12}$ This is in addition to feedingcare practices (breastfeeding, appropriate complementary feeding) and preventive health-care practices (immunizations, supplementation, deworming, prompt healthseeking behavior, safe sanitation, and safe drinking water). ${ }^{16,17}$ These behaviors are known to increase food intake, leading to a reduction in child undernutrition. ${ }^{8,12}$ In addition, responsive feeding builds emotional bonding between the pair, which is necessary for healthy growth. ${ }^{5,8}$ An abundance of evidence exists on the causes of undernutrition, including a high demand of nutrients for growth, poor food intake, poor feeding behaviors, and diseases.$^{18}$ Food intake is affected by the status of household food security, child-care and feeding practices, and diseases. ${ }^{17}$ Among all these causes, child-care practices, especially interactive behaviors during feeding, have received little attention when designing nutrition interventions, ${ }^{16}$ yet are an important element in improving dietary intake to reduce undernutrition. ${ }^{3,9,10,16}$

The purpose of the present study was to determine whether feeding the child slowly is associated with lower levels of stunting among young children. The data presented forms part of the first phase (cross-sectional baseline) of a cohort study aimed at evaluating the effect of poor water, poor sanitation, and poor hygiene practices on the nutritional status of children aged 6-24 months over a period of 12 months.

\section{Methods}

\section{Population and setting}

The study was conducted in the Monze district, which is about $200 \mathrm{~km}$ from the capital city of Lusaka in Zambia. The District Health Office identified study areas with a high prevalence of undernutrition, and purposively selected Hamangaba and Monze. In addition to a high prevalence of stunting in each of these communities, these locations were also selected based on their level of exposure to clean water and good sanitation. However, although the two areas are found approximately $114 \mathrm{~km}$ apart, in both areas people depend on agriculture and animal production for their livelihood, with the majority being small-scale farmers. The target group was households with children aged 6-24 months of age. Children with physical disabilities (e.g. disabled children) and children who were ill at the time of the study were excluded from the study. 


\section{Study design \& sampling}

This was a cross-sectional study. Study sites were selected purposely by the District Health Office targeting two areas: Njolamwanza, which was predominantly serviced with safe water and sanitary facilities, and Hamangaba, a poorly serviced area (control). This was a requirement of the main study, which aimed at examining the nutrition and health status of children in the two different areas that could be classified as exposure and control for the purpose of comparison. Census standard areas (CSAs) and standard enumerator areas (SEAs) were used to sample households using maps. Households in the study areas were listed to enable the random selection of households. A total of 295 households with children between 6 and 24 months were randomly selected; Njolamwanza (n:140) and Hamangaba (n:155). Only one child per household was selected randomly from children in the household between 6 and 24 months.

\section{Data collection}

Among the selected respondents, interviews and observations were conducted using a questionnaire and observation checklist, respectively, to collect information on socioeconomic and demographic factors, nutrition variables, anthropometric data, water, sanitation, and hygiene information. The data were collected by enumerators who were trained in anthropometric measurements and questionnaire administration. Anthropometric measurements were taken during data collection at household visits. Children's weights were measured using a Salter scale to the nearest $0.1 \mathrm{~kg}$. The length (measurement in recumbent position) was measured to the nearest $0.1 \mathrm{~cm}$ using a length-measuring board as recommended for infants and young children $0-24$ months or less than $85 \mathrm{~cm} .{ }^{19}$

The variable "feeding slowly" (with patience in an interactive manner) was measured as a single variable and as one of the ways among the several elements of responsive feeding (trying different foods, asking someone else to feed the child, helps the child to eat, and does not force-feed the child) mothers/caregivers use to motivate their children to eat, especially when they feel that the child has not eaten enough. A multiple-response questionnaire required the enumerator to mark all the ways the mother/caregiver indicated they used to motivate their children to eat.

The variable "type of food given to the child" was defined by two categories of thickness of porridge. The texture of thick porridge allows it to stay easily on the spoon without running off when the spoon is tilted, while thin porridge is the opposite of thick. The porridge pours out of the spoon when tilted. It is often fed from a cup or poured from the hand.

A food consumption score (FCS) was calculated by adding the frequency of consumption of different food groups by the child during the seven days before the survey. ${ }^{20}$ The FCS has been validated by the World Food Programme (WFP) for use in 
community household surveys as a proxy indicator of food security. ${ }^{20}$ Mothers/caregivers were asked to recall how many days in a week the child was given certain foods from eight groups (e.g. starches, legumes, fruits, vegetables, dairy, meats, oil, and sugar), which was multiplied by its weight to create a score. The weighted score ranges from o to 112. Three categories (as defined by WFP) of poor (o-21), borderline (21.5-35), and acceptable ( $>35$ ) food intake were used to determine the levels of food intake.

The World Health Organization (WHO) and United Nations Child Fund (UNICEF) ${ }^{21}$ provided the guide for quality of water as safe or unsafe water grouped as "improved" and "unimproved" water sources. An "improved water source" includes a piped water supply into the dwelling, piped water to a yard/plot, a public tap/standpipe, a tube well/borehole, a protected dug well, a protected spring, and rainwater. An "unimproved water source" includes an unprotected well, an unprotected spring, a cart with a small tank/drum, a water tanker-truck, and surface water.

\section{Data analysis}

The Emergency Nutrition Assessment (ENA) for Standardized Monitoring and Assessment of Relief and Transitions (SMART) programme ${ }^{22}$ was used to calculate the $\mathrm{z}$ scores used to determine the nutritional status of children using three anthropometric indices: weight-for-height, height-for-age, and weight-for-age. These were compared with the WHO growth standards using the ENA package. Malnutrition was determined as the proportion of children below -2 and -3 standard deviations (SDs) (z-scores) of all of the three indices, while overweight was the proportion of children with a weight-for-height above +2 z-scores. $^{6,19,23}$ IBM SPSS version 20 (Armonk, NY: IBM Corp.) was used for the other analyses. Prior to analysis, data were entered using the Epi data package. ${ }^{24}$ Thereafter, the first analyses were descriptive analyses of socio-demographic variables and other key variables, namely socioeconomic, demographic, water, sanitation and hygiene, and nutritional status. Logistic regressions were used to derive the association between these variables and the outcome variable, stunting. Prevalence was standardized-for-age using the national census (2010) in order to control for changes in the age structure. Cross-tabulations were conducted with stunting as the outcome variable to test for bivariate relationships.

Significant variables and other important variables that were not significant were placed in a multivariate logistic regression model to determine the associations of predictors in relation to the outcome variables. The distribution of age as a continuous variable conformed to normality as assessed by probability plots. Interactions were studied using the likelihood ratio test, and when identified, the terms were computed to allow estimation of the statistical effect of one of the variables separately for each level of the effectmodifying variable. Model diagnostics were performed using the maximum likelihood estimation (MLE) and the Hosmer-Lemeshow goodness-of-fit. The variables in the 
model were feeding slowly, being adjusted for age of child and mother, sex of child and household head, number of meals per day, thickness of food given to the child (whether pouring or dropping (thick) consistency), diseases suffered two weeks before the survey, vaccinations, deworming, water quality, hygiene status of mother and child, household size, and occupation of the household. Child age and type of food given were further adjusted between stunting and feeding slowly as likely cofounders.

\section{Ethics}

The protocol was approved by the ethics committee of the University of the Western Cape and Biomedical Ethics Committee of the University of Zambia, Ridgeway Campus (Assurance No. FW Aooooo338 IRBoooo1131 of IORGooo0774). Permission was also granted by the Ministry of Health and the District Medical Office in Monze. Informed signed consent was obtained from the mothers/caregivers of the participating households. The research presented no known risks associated with participating in the study, and neither were there any direct benefits to the participants.

\section{Results}

\section{Participation and distribution}

The sample included 295 participants and the mean age of children was 14.4 (SD 5.9) months, of which $54 \%$ were females and $46 \%$ were males (Table 1). The median age was 14.7 (IQR 8.8, 19.6) months. The households were mainly headed by males who were middle-aged, and the majority had only attained a primary education. Unlike household heads, most mothers/caregivers were in the early childbearing age period, having mostly attained a primary education. Farming was the main livelihood activity in the study areas. 
Table 1. Socio-demographic data for households with infants 6-24 months in the study areas.

\begin{tabular}{|c|c|c|c|c|}
\hline & Overall & $\begin{array}{c}\text { Hamangaba } \\
\mathrm{N}=155 \\
\end{array}$ & $\begin{array}{c}\text { Njolamwanza } \\
\mathrm{N}=140 \\
\end{array}$ & \\
\hline Variable & $\mathrm{N}(\%)$ & $\mathrm{N}(\%)$ & $\mathrm{N}(\%)$ & $P$ value \\
\hline Age of household head $15-30$ years & $96(33.0)$ & $51(33.1)$ & $45(32.8)$ & 0.97 \\
\hline $31-45$ years & $126(43.3)$ & $66(42.9)$ & $60(43.8)$ & \\
\hline Over 45 years & $69(23.7)$ & $37(24.0)$ & $32(23.4)$ & \\
\hline Sex of household head Female & $42(14.3)$ & $24(15.5)$ & $18(12.9)$ & 0.63 \\
\hline Male & $252(85.7)$ & $131(84.5)$ & $121(87.1)$ & \\
\hline Marital status of household head & & & & 0.13 \\
\hline Not married & $40(13.7)$ & $17(11.1)$ & $23(16.5)$ & \\
\hline Married & $252(86.3)$ & $136(88.9)$ & $116(83.5)$ & \\
\hline Education level of household head & & & & 0.05 \\
\hline None & $9(3.1)$ & $2(1.3)$ & $7(5.1)$ & \\
\hline Primary & $158(54.1)$ & $92(59.7)$ & $66(47.8)$ & \\
\hline Secondary & $112(38.4)$ & $53(34.4)$ & $59(42.8)$ & \\
\hline Above secondary & $13(4.5)$ & $7(4.5)$ & $6(4.3)$ & \\
\hline Age of mother $15-30$ years & $186(63.7)$ & $96(63.2)$ & $90(64.3)$ & 0.26 \\
\hline $31-45$ years & $93(31.8)$ & $51(33.6)$ & $42(30.0)$ & \\
\hline Over 45 years & $13(4.5)$ & $5(3.3)$ & $8(5.7)$ & \\
\hline Education of mother/caregiver None & $6(2.5)$ & $1(0.8)$ & $5(4.4)$ & 0.05 \\
\hline Primary & $139(58.4)$ & $81(64.8)$ & $58(51.3)$ & \\
\hline Secondary & $89(37.4)$ & $42(33.6)$ & $47(41.6)$ & \\
\hline Above secondary & $4(1.7)$ & $1(0.8)$ & $3(2.7)$ & \\
\hline Occupation household head & & & & 0.09 \\
\hline Farmer & $235(86.4)$ & $126(89.4)$ & $109(83.2)$ & \\
\hline Teacher & $8(2.9)$ & $3(2.1)$ & $5(3.8)$ & \\
\hline Businessman & $15(5.5)$ & $9(6.4)$ & $6(4.6)$ & \\
\hline House/farmer worker & $7(2.6)$ & $1(0.7)$ & $6(4.6)$ & \\
\hline Driver/conductor & $3(1.1)$ & $1(0.7)$ & $2(1.5)$ & \\
\hline Other occupations & $4(1.5)$ & $1(0.7)$ & $3(2.3)$ & \\
\hline Household size $\leq 5$ & $200(67.8)$ & $101(65.2)$ & $99(70.7)$ & 0.40 \\
\hline$>5$ & $95(32.2)$ & $54(34.8)$ & $41(29.3)$ & \\
\hline \multicolumn{5}{|l|}{ Total income of household } \\
\hline$<100$ & $83(28.4)$ & $45(29.2)$ & $38(27.5)$ & 0.77 \\
\hline $101-1000$ & $169(57.9)$ & $89(57.8)$ & $80(58.0)$ & \\
\hline$>1000$ & 40 (13.7) & $20(13.0)$ & $20(14.5)$ & \\
\hline Sex of children Female & $158(53.7)$ & $88(56.8)$ & $70(50.4)$ & 0.08 \\
\hline Male & $136(46.3)$ & $67(43.2)$ & $69(49.6)$ & \\
\hline Age of child below 12 months & $126(42.7)$ & $77(49.0)$ & $50(35.7)$ & $0.01^{*}$ \\
\hline between $12 \& 18$ months & $90(23.7)$ & $36(22.6)$ & $35(25.0)$ & \\
\hline above 18 months & $99(33.6)$ & $44(28.4)$ & $55(39.3)$ & \\
\hline Water quality unimproved (unsafe) & $86(29.3)$ & $67(44.4)$ & $19(13.3)$ & $<0.001^{* * * *}$ \\
\hline Improved (safe) & $208(70.7)$ & $84(55.6)$ & $124(86.7)$ & \\
\hline
\end{tabular}

${ }^{*} p<0.05,{ }^{* * *} p<0.001$ 
Table 2. Prevalence of malnutrition among children 6-24 months in the study areas.

\begin{tabular}{|c|c|c|c|c|c|}
\hline & & $\underline{\text { Severe }(<-3 z \text {-score })}$ & $\begin{array}{c}\text { Moderate } \\
(\geq-3 \text { and }<-2 \text { z-score })\end{array}$ & $\begin{array}{c}\begin{array}{c}\text { Normal } \\
(\geq-2 \text { z score })\end{array} \\
\end{array}$ & \\
\hline & $\mathrm{N}$ & N (\%) & N (\%) & N (\%) & $p$-value \\
\hline \multicolumn{6}{|l|}{ Wasting } \\
\hline Total & 288 & $7(2.4)$ & $12(4.2)$ & $249(86.5)$ & 0.342 \\
\hline Hamangaba & 153 & $6(4.1)$ & $6(4.1)$ & $126(85.1)$ & \\
\hline Njolamwanza & 135 & $1(0.7)$ & $6(4.3)$ & $123(87.9)$ & \\
\hline \multicolumn{6}{|l|}{ Stunting } \\
\hline Total & 292 & 33 (11.3) & $65(22.3)$ & $194(66.4)$ & 0.561 \\
\hline Hamangaba & 150 & $12(8.0)$ & $36(24.0)$ & $102(68.0)$ & \\
\hline Njolamwanza & 142 & $21(14.8)$ & $29(20.4)$ & $92(64.8)$ & \\
\hline \multicolumn{6}{|l|}{ Underweight } \\
\hline Total & 290 & $3(1.0)$ & $32(10.7)$ & $256(88.3)$ & 0.682 \\
\hline Hamangaba & 148 & $2(1.4)$ & $17(11.5)$ & $129(87.2)$ & \\
\hline Njolamwanza & 142 & $1(0.7)$ & $14(9.9)$ & $127(89.4)$ & \\
\hline
\end{tabular}

\section{Child malnutrition}

The two areas were generally comparable, except for age distribution, education status of the mother/caregiver $(p=0.045)$, and water quality by which the two areas differed significantly. Overall, the prevalence of stunting was $33.6 \%$ (95\%CI $28.18 \%, 39.02 \%)$ and did not differ significantly between the two areas: $32 \%$ versus $35.2 \%$ for Hamangaba and Njolamwanza, respectively $(p=0.17$ ) (Table 2). In contrast, the proportion of underweight was much lower than stunting: $12.9 \%$ in Hamangaba and $10.6 \%$ in Njolamwanza . The overall proportion of wasting was $6.6 \%$, being $8.2 \%$ in Hamangaba and $5 \%$ in Njolamwanza. There were no statistical differences between the two areas regarding stunting, underweight, and wasting.

\section{Responsive feeding practices and general feeding practices}

Responsive feeding practices observed during the study are shown in Table 3. Overall, it is interesting to note that only $10.2 \%$ of mothers/caregivers fed their children slowly and only $35.1 \%$ helped their children to eat. Less than $30 \%$ tried another food and less than $10 \%$ asked another person to feed the child. On the positive side, a low percent (6.7\%) forced their children to eat. Table 4 provides data on general feeding practices. In the youngest age group, more than $87 \%$ of the caregivers reported giving children less than three meals a day, while this decreased to $12.8 \%$ in the older group. 
Table 3. Responsive feeding practices among children 6-24 months in the study areas.

\begin{tabular}{lccc}
\hline & Overall & Hamangaba & Njolamwanza \\
Responsive feeding practices & Number (\%) & Number (\%) & Number (\%) \\
\hline Helps child to eat Yes & $99(35.1)$ & $48(33.1)$ & $51(37.2)$ \\
No & $183(64.9)$ & $97(66.9)$ & $86(62.8)$ \\
Does not force-feed child Yes & $264(93.3)$ & $9(6.2)$ & $10(7.3)$ \\
No & $19(6.7)$ & $137(93.8)$ & $127(92.7)$ \\
Tries another food Yes & $74(26.1)$ & $39(26.7)$ & $35(25.5)$ \\
No & $209(73.9)$ & $107(73.3)$ & $102(74.5)$ \\
Feeds slowly (patiently) Yes & $29(10.2)$ & $21(14.4)$ & $8(5.8)$ \\
No & $254(89.8)$ & $125(85.6)$ & $129(94.2)$ \\
Asks another person to feed the child Yes & $17(6.0)$ & $5(3.4)$ & $12(8.8)$ \\
No & $266(94.0)$ & $141(96.6)$ & $125(91.2)$ \\
\hline
\end{tabular}

Table 4. Child feeding practices by age among children 6-24 months living in Monze District.

\begin{tabular}{|c|c|c|c|c|}
\hline Variable & $\begin{array}{r}\text { Overall } \\
\text { No. (\%) } \\
\end{array}$ & $\begin{array}{c}\leq 12 \text { months } \\
\text { No. }(\%)\end{array}$ & $\begin{array}{c}>12 \text { months } \\
\text { No. (\%) }\end{array}$ & $p$ \\
\hline \multicolumn{5}{|c|}{ No. of main meals/day } \\
\hline$<3$ meals/day & 39 (13.9) & $34(87.2)$ & $5(12.8)$ & \multirow[t]{2}{*}{0.000} \\
\hline$\geq 3$ meals $/$ day ${ }^{a}$ & $241(86.1)$ & $72(29.9)$ & $169(70.1)$ & \\
\hline \multicolumn{5}{|c|}{ No. of snacks/day } \\
\hline$<2$ snacks & $250(89.6)$ & $100(40.0)$ & $150(60.0)$ & \multirow[t]{2}{*}{0.017} \\
\hline$\geq 2$ snacks $^{\mathrm{b}}$ & $29(10.4)$ & $5(17.2)$ & $24(82.8)$ & \\
\hline \multicolumn{5}{|c|}{ Reduced child meal sizes ${ }^{c}$} \\
\hline Yes & $62(22.7)$ & $21(33.9)$ & $41(66.1)$ & \multirow[t]{2}{*}{0.656} \\
\hline No & $211(77.3)$ & $78(37.0)$ & $133(63.0)$ & \\
\hline \multicolumn{5}{|c|}{ Not eat the ad lib ${ }^{d}$} \\
\hline Yes & $18(6.7$ & $7(38.9)$ & $11(61.1)$ & \multirow[t]{2}{*}{0.779} \\
\hline No & $250(93.3$ & $89(35.6)$ & $161(64.4)$ & \\
\hline \multicolumn{5}{|c|}{ Food consumption score ${ }^{e}$} \\
\hline$\leq 35$ point score & $41(14.4)$ & $29(70.7)$ & $12(29.3)$ & \multirow[t]{2}{*}{.000} \\
\hline$>35$ point score & $243(85.6)$ & $81(33.3)$ & $162(66.7)$ & \\
\hline
\end{tabular}

${ }^{a}$ Ideally the child should have three meals a day

${ }^{b}$ Ideally the child should have at least two snacks a day

${ }^{c}$ Meals are reduced in size when the home is food insecure

${ }^{d}$ Feeding times are reduced and child does not eat whenever hungry

${ }^{e}$ A score of at least 35 is acceptable. Less indicates food insecurity

It is interesting to note that in the older group, $82.8 \%$ of caregivers reported giving children two or more snacks (between meals) a day. Caregivers reported reducing meal sizes in one-third of the young children and two-thirds of the older children. Seven percent of caregivers reported that children were not allowed to eat all day (ad lib) due to a lack of food in the home at times. In terms of having an FCS greater than 35, which is regarded as being acceptable, $66.7 \%$ of the older group met this criteria. However, only $33 \%$ of the younger children had an FCS greater than 35 . 


\section{Factors associated with stunting}

Overall, multivariate analysis showed that feeding the child slowly, together with age group and deworming, were predictors of stunting (Table 5). In children where the practice of feeding the child slowly was reported, stunting was less prevalent than in children where this was not practiced [AOR (adjusted odds ratio) 0.28; 95\% CI: 0.11, 0.72]. This was the most prominent when the food ingested was thick [OR 0.46; 95\% CI: 0.23, 0.92]. In addition, data from both study areas showed that stunting was less likely in children older than one year than in the younger age group [AOR 0.26; 95\%CI: 0.11, 0.61] as well as in children who had been dewormed [AOR 0.50; 95\% CI: 0.26, 0.95], which was the case in Hamangaba [AOR 0.24; 95\% CI: 0.09, 0.64] but not in Njolamwanza. Feeding the child slowly in children older than one year showed a much stronger reduced likelihood of stunting than younger children not fed slowly [AOR 0.32; 95\% CI: $0.14,0.75, p=0.008$ ]) (Table 6). When type of food given, deworming, and water quality were added to the model, it did not change the effect of feeding slowly. This means that even though children above one year are less likely to be stunted, when feeding slowly becomes part of the child's feeding practice, stunting is likely to be reduced by $68 \%$ in model 1 and by $71 \%$ in model 2. 
Table 5. Association of "feeding slowly" with stunting (height for age $<-2 \mathrm{SD}$ ) among infants 6-24 months in the study areas.

\begin{tabular}{|c|c|c|c|c|c|}
\hline \multirow[b]{2}{*}{ Predictor } & \multirow[b]{2}{*}{$\begin{array}{c}\text { Prevalence } \\
\text { Total (\%) }\end{array}$} & \multirow{2}{*}{$\begin{array}{c}\text { Univariate } \\
\text { Pooled } \\
\text { OR }(95 \% \mathrm{Cl})\end{array}$} & \multicolumn{3}{|c|}{ Multivariate } \\
\hline & & & $\begin{array}{l}\text { Hamangaba } \\
\text { OR }(95 \% \mathrm{Cl})\end{array}$ & $\begin{array}{c}\text { Njolamwanza } \\
\text { OR }(95 \% \text { Cl) }\end{array}$ & $\begin{array}{c}\text { Pooled } \\
\text { OR }(95 \% \text { Cl) }\end{array}$ \\
\hline Feeding child slowly & $29(10.2)$ & $0.45(0.21-0.98)$ & $0.23(0.08,1.02)$ & $0.16(0.02,1.32)$ & $0.28(0.11,0.72)$ \\
\hline Yes & & p $0.045^{*}$ & p 0.054 & p 0.089 & $p=0.008^{* *}$ \\
\hline Sex of child & $136(46.3)$ & $0.82(0.50,1.34)$ & $1.03(0.40,2.66)$ & $0.58(0.24,1.36)$ & $0.76(0.42,1.35)$ \\
\hline Male & & p 0.427 & p 0.955 & p 0.208 & p 0.347 \\
\hline Age of child & $174(59.0)$ & $0.22(0.13,0.39)$ & $0.29(0.08,0.95)$ & $0.23(0.06,0.88)$ & $0.26(0.11,0.61)$ \\
\hline$>12$ months & & p $0.000 * * *$ & p. $.040^{*}$ & p $0.032^{*}$ & p $0.002^{* * *}$ \\
\hline No. of main meals & $241(86.1)$ & $0.43(0.19,0.98) \mathrm{p}$ & $1.19(0.29,4.86)$ & $0.69(0.10,4.92)$ & $1.09(0.39,3.00)$ \\
\hline$>2$ meals & & $0.045^{*}$ & p 0.805 & P 0.712 & p 0.875 \\
\hline Child's diseases & $37(12.6)$ & $0.49(0.24,0.97)$ & $1.78(0.37,8.57)$ & $0.37(0.12,1.12)$ & $0.64(0.26,1.51)$ \\
\hline None & & p $0.042 *$ & p 0.473 & p 0.077 & p 0.310 \\
\hline Sex of household & $252(85.7)$ & $1.16(0.58,2.31)$ & $0.88(0.24,3.23)$ & $0.580(0.16,2.15)$ & $0.10(0.39,2.07)$ \\
\hline head Male & & p 0.671 & p 0.848 & p 0.414 & p 0.802 \\
\hline Household size & $200(67.8)$ & $1.23(0.72,2.09)$ & $0.71(0.23,2.16)$ & $1.69(0.64,4.44)$ & $1.14(0.57,2.25)$ \\
\hline $5 \leq$ members & & 0.443 & 0.545 & p 0.291 & p 0.716 \\
\hline Age of the mother & $106(36.3)$ & $0.64(0.38,1.05)$ & $0.66(0.25,1.75)$ & $0.97(0.39,2.40)$ & $0.78(0.42,1.44)$ \\
\hline$>31$ years & & P 0.076 & p 0.402 & p 0.941 & p 0.426 \\
\hline Water & $208(70.7)$ & $0.82(0.48,1.41)$ & $0.92(0.35,2.48)$ & $0.64(0.16,2.50)$ & $0.96(0.50,1.87)$ \\
\hline Safe & & p 0.474 & p 0.876 & p 0.519 & p 0.906 \\
\hline History of & $147(50.7)$ & $0.35(0.21,0.59)$ & $0.24(0.09,0.64)$ & $0.96(0.36,2.56)$ & $0.50(0.26,0.95)$ \\
\hline deworming Yes & & p. $.000 * * *$ & p. $.004 * *$ & p 0.939 & p $0.035^{*}$ \\
\hline Vaccinations & $204(69.2)$ & $0.32(0.17,0.58)$ & $0.63(0.19,2.07)$ & $1.32(0.37,4.76)$ & $0.98(0.44,2.18)$ \\
\hline Yes & & p $0.000 *$ & p 0.447 & p 0.670 & p 0.962 \\
\hline Type of food given & $221(79.8)$ & $0.46(0.23,0.92)$ & $0.78(0.19,3.11)$ & $1.16(0.25,5.43)$ & $0.88(0.34,2.27)$ \\
\hline Thick food & & p $0.027^{*}$ & p 0.725 & p 0.852 & p 0.788 \\
\hline Occupation & $37(13.6)$ & $0.54(0.27,1.10)$ & $0.20(0.04,0.90)$ & $1.37(0.44,4.22)$ & $0.63(0.28,1.46)$ \\
\hline \multirow{9}{*}{$\begin{array}{l}\text { household hea } \\
\text { Other } \\
\text { occupations }^{\mathrm{a}}\end{array}$} & & p 0.090 & p .036* & p 0.585 & p 0.283 \\
\hline & & & Hosmer and & Hosmer and & Hosmer and \\
\hline & & & Lemeshow test $=$ & Lemeshow test $=$ & Lemeshow test $=$ \\
\hline & & & 0.282 & 0.132 & 0.159 \\
\hline & & & Cox \& Snell $R^{2}=$ & Cox \& Snell $R^{2}=$ & Cox \& Snell $R^{2}$ \\
\hline & & & 0.391 Nagelkerke $\mathrm{R}^{2}$ & 0.180 & $=0.218$ \\
\hline & & & chi-square $=42.150$, & Nagelkerke $\mathrm{R}^{2}$ chi- & Nagelkerke $\mathrm{R}^{2}$ \\
\hline & & & $p=0.000$ & square $=16.590$, & chi-square = \\
\hline & & & & $\mathrm{p}$ & $\begin{array}{l}42.195 \\
p<0.000\end{array}$ \\
\hline
\end{tabular}

Note: the category value is the opposite of the category listed ${ }^{*} p<0.05 ;{ }^{* *} p<0.01 ;{ }^{* * *} p<0.001 .{ }^{a}$ the opposite is farmer; $\mathrm{N}=295$.

\section{Discussion}

Overall, there is a high prevalence of stunting in this population. Stunting is affected by various factors that include, among others, biological ones (age group of the child), environmental (worms), and child-care behaviors (child feeding practices). 
Table 6. Association of "feeding slowly" with stunting (height for age < -2SD) among infants 6-24 months in Hamangaba and Njolamwanza areas.

\begin{tabular}{|c|c|c|c|c|c|}
\hline Predictor & Prevalence & $\begin{array}{c}\text { Adjusted } \\
\text { OR (95\% Cl) } \\
\text { Model I }\end{array}$ & $\begin{array}{c}\text { Adjusted } \\
\text { OR }(95 \% \mathrm{Cl}) \\
\text { Model II }\end{array}$ & Hamangaba & Njolamwanza \\
\hline \multicolumn{6}{|l|}{ Feeding slowly } \\
\hline No & $254(89.8)$ & 1 & 1 & 1 & 1 \\
\hline \multirow[t]{2}{*}{ Yes } & $29(10.2)$ & $0.32(0.14,0.75)$ & $0.29(0.12,0.70)$ & $0.35(0.11,1.09)$ & $0.14(0.02,0.90)$ \\
\hline & & p 0.008** & & $p=0.07$ & $p=0.04^{*}$ \\
\hline \multicolumn{6}{|l|}{ Child's age } \\
\hline 6-12 months & $121(41.0)$ & 1 & 1 & 1 & 1 \\
\hline \multirow[t]{2}{*}{$>12$ months } & $174(59.0)$ & $0.21(0.11,0.38)$ & $0.26(0.13,0.52)$ & $0.30(0.12,0.76)$ & $0.22(0.07,0.65)$ \\
\hline & & p $0.000^{* * *}$ & & p $0.01^{*}$ & p $0.006 * *$ \\
\hline \multicolumn{6}{|l|}{$\begin{array}{l}\text { Type of food } \\
\text { given }\end{array}$} \\
\hline Less thick & $56(20.2)$ & & 1 & 1 & 1 \\
\hline Thick food & $221(79.8)$ & & $1.04(0.45,2.40)$ & $\begin{array}{l}0.89(0.29,2.75) \\
\text { p } 0.84\end{array}$ & $\begin{array}{l}1.68(0.44,6.37) \\
\text { p } 0.45\end{array}$ \\
\hline Deworming No & & & 1 & 1 & \\
\hline \multirow[t]{2}{*}{ Yes } & & & $0.51(0.28,0.92)$ & $0.27(0.11,0.63)$ & $0.94(0.40,2.21)$ \\
\hline & & & & p $0.002^{* *}$ & p 0.89 \\
\hline \multicolumn{6}{|l|}{ Water quality } \\
\hline Unsafe & & & 1 & & \\
\hline \multirow[t]{9}{*}{ Safe } & & & $0.93(0.51,1.72)$ & $0.87(0.38,2.00)$ & $0.89(0.28,2.86)$ \\
\hline & & & & p 0.75 & $\mathrm{p} 0.84$ \\
\hline & & & Total & Hamangaba Hosmer \& & Njolamwanza \\
\hline & & & Hosmer \& & Lemeshow test $=0.963$ & Hosmer \& \\
\hline & & & Lemeshow & Cox \& Snell & Lemeshow \\
\hline & & & test $=0.729$ Cox \& & $R^{2} 0.198$ Nagelkerke & test $=0.296$ \\
\hline & & & $\begin{array}{l}\text { Snell } \\
R^{2}=0.134\end{array}$ & $R^{2}=0.275$ & $\begin{array}{l}\text { Cox \& Snell } \\
R^{2} 0.101\end{array}$ \\
\hline & & & Nagelkerke & & Nagelkerke \\
\hline & & & $R^{2}=0.184$ & & $\mathrm{R}^{2=} 0.138$ \\
\hline
\end{tabular}

${ }^{*} p<0.05 ;{ }^{* *} p<0.01 ;{ }^{* * *} p<0.001$.

The finding that age is associated with stunting has also been reported elsewhere. ${ }^{25,26}$ Unlike most studies, ${ }^{27,28}$ the present study shows that as children grow older, the risk of stunting is reduced, especially above the age of one year. There are several factors that could have changed with age that can be attributed to this scenario. These may include reduction of disease episodes as children grew older or they may have received an improved diet. ${ }^{29-31}$

The association of "worm infestations" with stunting is expected due to poor water and sanitation services and high levels of infection (data not shown) in Hamangaba. High morbidity in children (as in this study) negatively affects child growth. ${ }^{32-34}$ This adds to existing evidence on the important role deworming plays in a poor environment in improving child survival. Soil-transmitted helminths (STHs) tend to flourish in poor environments such as those with poor sanitation and hygiene, and water that is not safe. ${ }^{35}$ Therefore, deworming offers an opportunity to treat the 
supposedly unreported STHs in the study areas. A review by Hotez et al that in Guatemala and along the north Pacific coast of South America, helminths were associated with underweight and stunting, respectively. Furthermore, the finding that dewormed children were less likely to be stunted support the evidence that STHs, just like other infections, tend to be associated with micronutrient deficiencies such as chronic anemia, leading to a compromised immune system..$^{37-39}$ The end result may be a double state of increased infestations and infection among the affected children.

Feeding the child slowly was strongly and negatively associated with stunting. We believe that this is reasonable because child feeding behaviors of this kind affect food intake and child growth since the infant will eat more when fed by the mother in a responsive manner. ${ }^{8,12,16}$ Furthermore, it provides an opportunity for the mother and baby pair to interact during feeding, which may lead to building of the bond between them (ibid). Feeding slowly (exercising patience) while feeding may reduce the likelihood of using forceful means of feeding and unattended self-feeding, which have been reported to contribute to less food intake. ${ }^{1-14}$ Similar findings to this study have been reported by other researchers. Ha et al. ${ }^{14}$ found that when responsive feeding behaviors such as non-pressuring or forcing and positive verbalization to the child are part of the eating episodes, food acceptance by the children was improved. In Ghana, Nti and Lartey ${ }^{40}$ reported that the children of caregivers who were the most responsive during feeding demonstrated a healthier appetite and interest in food. Although feeding slowly was observed to be an important factor, it was practiced by few mothers $(10.2 \%)$ in this study. Several researchers have reported that few caregivers practice these key feeding behaviours., ${ }^{3,14}$ It is therefore clear that even if age is associated with stunting, it is possible to further improve its effect when other child-care practices such as feeding the child slowly and deworming are part of the way of feeding and caring for the child. Similarly, clean water, good sanitation, and hygiene play an important role in preventing diseases. The association among feeding slowly, deworming, and age of the child with stunting may be an indication that supporting interventions that promote good child feeding and caring behaviors can reduce stunting. This may be true for interventions, especially those addressing complementary feeding and environmental health. Targeting caregivers by providing them with information on such behaviors and supporting them through community networks would increase their knowledge base and the desire to take action. The finding that stunting was not different in the two sites given the large difference in water and sanitation facilities was unexpected given the effect that disease has on nutrition. However, it is also an indication that there are other factors that we did not study, which could have explained the reason for this situation. A bigger study would probably assist in addressing such challenges. We are aware that in surveys like this, there may be many inherent biases. Since most of the responses were reported by caregivers, overreporting was possible, and would have led to the overreporting of some variables.

Regarding the variable "feeding the child slowly," a negative social desirability effect may have occurred. Mothers/caregivers may have opted not to report on the latter, 
thinking it to be an undesirable behavior. This may have been a possible explanation why those that reported feeding slowly were few. Furthermore, the researchers had no control over the services that were being provided in the two study areas by the various service providers such as the Department of Health and nongovernmental organizations. This could also have resulted in bias.

The study had limitations. Being a cross-sectional study, the study design has limited power to detect associations and therefore results should be used with caution. Such a study could not allow sufficient time to observe improvements in the outcome of interest. Future studies involving methods that can allow making better inferences could be considered. Furthermore, the study focused more on response from caregivers instead of long observational periods, which are more reliable to observe the actual practice/behavior.

\section{Conclusion}

We have observed that feeding a child slowly, a component of responsive feeding, the use of thicker (more energy-dense) food, age of the child, and the practice of deworming were all negatively associated with stunting. These findings illustrating an association between feeding children slowly and stunting emphasize that feeding practices in general are important elements to consider in the fight against the burden of malnutrition. It was also found that stunting was the lowest among children older than one year who consumed thicker foods, further indicating that stunting is also associated with the quality of diet. Generally, these findings suggest that feeding practices coupled with types of food and infection control should be considered in behavioral interventions for reducing the stunting burden in this population. In addition, deworming, which is already supported by health authorities in Zambia, should continue to be promoted in addition to adequate sanitation, safe water, and good hygiene. Increasing the awareness of caregivers about these findings is extremely important so that continued individual and community participation is passed on to new generations, thereby promoting good community practices such as feeding slowly and acceptable food preparation. It is recommended that whenever possible, health and nutrition promotion community-based strategies on primary health care should include information on responsive feeding.

\section{Acknowledgments}

We also acknowledge the various contributions made by the following people for this work: the members of the UNZA-SoM SACORE Steering Committee (Dr Margret Maimbolwa, Dr Paul Kelly, Dr Hellen Ayles, \& Dr Charles Michelo). We also acknowledge the Monze DHMT for allowing the study and the support rendered during the study.

\section{Disclosure statement}

The author(s) declare that they have no competing interests. 


\section{Funding}

We acknowledge the support provided by the Research Support Centre at the University of Zambia, School of Medicine (UNZA-SoM), through the Southern African Consortium for Research Excellence (SACORE), which is part of the African Institutions Initiative Grant of the Wellcome Trust.

\section{Notes on contributors}

RM and NPS conceptualized the study, RM was actively involved in implementation of the study. RM and CM performed the data analyses. RM, NPS, and CM were involved in the writeup of the study. 


\section{References}

1. United Nations Child Fund, World Health Organization. Joint UNICEF -WHO The World Bank Child Malnutrition Database : Estimates for 2012 and Launch of Interactive Data Dashboards. New York: United Nations ChildFund; Geneva: WHO; 2013:2-4.

2. United Nations Child Fund, Improving Child Nutrition. The Achievable Imperative for Global Progress [Internet]. New York, USA: UNICEF; 2013:1-132. http://scholar.google.com/scholar?hl=en\&btnG=Search\&q=intitle:IMPROVING+CHI $\mathrm{LD}+$ NUTRITION+ The+achievable+imperative+for+global+progress\#o .

3. Central Statistical Office, Ministry of Health, TDRC, UNZA, MACRO International. Zambia Demographic and Health Survey 2013-14. Lusaka, Zambia: Ministry of Health; 2014.

4. Black RE, Allen LH, Bhutta ZA, et al. Maternal and child undernutrition 1: maternal and child undernutrition : global and regional exposures and health consequences. Lancet. 2008;371:5-22. doi:10.1016/So140-6736(07)61690-0.

5. Black MM, Aboud FE. Responsive feeding is embedded in a theoretical framework of responsive parenting. $J$ Nutr. 2011;141:490-494. doi:10.3945/jn.110.129973.

6. Dewey KG BK. Why Stunting Matters. Washington, D.C: Alive and Thrive, FHI 360, Washington, DC; 2010:1-7.

7. Engle P, Pelto G. Responsive feeding: implications for policy and program $\begin{array}{llll}\text { implementation. } & J & \text { Nutr. 2011;141:508-511. }\end{array}$ http://jn.nutrition.org/content/141/3/508.short.

8. Harbron J, Najaar B. Paediatric food-based dietary guidelines for South Africa: responsive feeding: establishing healthy eating behaviour early on in life. $S$ Afr $J$ Clin Nutr. 2013;26(3):141-149.

9. Pan American Health Organization. Guiding Principles for Complementary Feeding of the Breastfeed Child. Washington, D.C: PAHO; 2003.

10. ACC/SCN. Lutter C. Meeting the Challenges to Improve Complementary Feeding. Scn News. 2003; USAID. https://www.popline.org/node/233102. Accessed December 12, 2017.

11. Aboud FE, Moore AC, Akhter S. Effectiveness of a community-based responsive feeding programme in rural Bangladesh : a cluster randomized field trial. Matern Child Nutr. 2008;4(2008):275-286. doi:10.1111/j.1740-8709.2008.00146.x.

12. Satter ME. The feeding relationship. Am J Diet Assoc. 1986;86:352-356.

13. Brown A, Lee MD Early influences on child satiety-responsiveness: the role of weaning style. Pediatr Obes 2013 Dec 17; 1-10. http://www.ncbi.nlm.nih.gov/pubmed/24347496. Accessed December 18, 2014.

14. Ha PB, Bentley ME, Pachón H, et al. Caregiver styles of feeding and child acceptance of food in rural Viet Nam. Food Nutr Bull. 2002;23(4):92-98. doi:10.1177/15648265020 234S213.

15. Stewart CP, Iannotti L, Dewey KG, et al. Contextualising complementary feeding in a broader framework for stunting prevention. Matern Child Nutr [Internet]. 2013 Sep;9 (Suppl 2):27-45. http://www.ncbi.nlm.nih.gov/pubmed/24074316. Accessed December 10, 2014. 
16. Amugsi DA, Mittelmark MB, Lartey A, et al. Influence of childcare practices on nutritional status of Ghanaian children : a regression analysis of the Ghana Demographic and Health Surveys. BMJ Open. 2014;4:1-10. doi:10.1136/bmjopen2014-005340.

17. UNICEF. The State of the World's Children. New York, USA: Oxford University Press; 1998.

18. Imdad A, Yakoob MY, Bhutta Z. Impact of maternal education about complementary feeding and provision of complementary foods on child growth in developing countries. BMC Public Health. 2011 Jan;11(Suppl 3):1-14. http://www.pubmedcentral.nih.gov/articlerender.fcgi?artid=3231899\&tool=pmcentrez \&rendertype=abstract. Accessed December 10, 2014.

19. De Onis M, Blössner M. Database on Child Growth and Malnutrition. Geneva:WHO; 1997.

20. Wiesman D, Bassett L, Benson T, et al. Validation of the World Food Programme's food consumption score and alternative indicators of household food security. Int Food Policy Res Inst. https://books.google.co.za/books?hl=en\&id=egtPwZdWR8IC\&oi= fnd\&pg $=$ PR9\&dq=World + food + program + food + consumption + score\&ots $=\mathrm{Ao} 3 \mathrm{PPFr}-$ zW\&sig=ExYmdSu62E95_KEkRX4fd8zhqvM\#v=onepage\&q=World\%2ofood\%20pro gram\%2ofood\%20consumption\%20score\&f=false. Accessed May 15, 2017.

21. WHO and UNICEF. Core Questions on Drinking-Water and Sanitation for Household Surveys. Geneva, Swizerland: WHO; 2006.

22. SMART Methodology. ENA for SMART - Software for Emergency Nutrition Assessment. http://www.nutrisurvey.de/ena_beta/ena-epiinfo/index.htm. Accessed December 12, 2017.

23. CDC and WFP. A Manual: Measuring and Interpreting Malnutrition and Mortality. Rome: FAO; 2005.

24. IBM. IBM SPSS Statistics. http://www-01.ibm.com/support/docview.wss?uid= swg1PM54938. Accessed December 12, 2017. Published 2012.

25. Central Statistical Office (CSO), Ministry of Health (MOH), Tropical Diseases Research Centre (TDRC), University of Zambia, Macro International Inc. Zambia Demographic and Health Survey 2007. Lusaka, Zambia. https://www.dhsprogram.com/Where-We-Work/CountryMain.cfm?ctry_id=47\&c=Zambia\&Country $=$ Zambia\&cn $=\& r=1$. Accessed December 12, 2017. Published 2009.

26. Van de Poel E., Hosseinpoor A.R., Speybroeck N., Van Ourti T., Vega J. Malnutrition and the disproportional burden on the poor : the case of Ghana. Int $J$ Equity Heal. 2007;6(21):1-12.

27. Ramli, Agho K.E., Inder, K.J., Bowe, S.J., Jacobs, J., Dibley, M.J. Prevalence and risk factors for stunting and severe stunting among under-fives in North Maluku province of Indonesia. BMC Pediatr. 2009;9(64):1-10. doi:10.1186/1471-2431-9-64.

28. Kikafunda JK, Walker AF, Collett D, et al. Risk factors for early childhood malnutrition in Uganda. Pediatrics. 1998;102(4):1-10. doi:10.1542/peds.102.4.e45. 
29. Richard SA, Black RE, Gilman RH, et al. Catch-up growth occurs after diarrhea in $\begin{array}{llll}\text { early childhood. } & J & \text { 2014;144(6):965-971. }\end{array}$ http://www.ncbi.nlm.nih.gov/pubmed/24699805.

30. Garza C. Commentary: please sir, I want some more (and something else). Int J Epidemiol. 2015:1-3. http://www.ije.oxfordjournals.org/cgi/doi/10.1093/ije/dyv299.

31. Paudel R, Pradhan B, Wagle RR, et al. Risk factors for stunting among children: a community based case control study in Nepal. Kathmandu Univ Med J. 2011;10 (39):18-24. http://www.ncbi.nlm.nih.gov/pubmed/23434956.

32. ACC/SCN. Third Report on the World Nutrition Situation. Geneva: WHO; 1997.

33. Schmidt MK, Muslimatun S, West CE, et al. Nutritional status and linear growth of indonesian infants in west java are determined more by prenatal environment than by postnatal factors. $J$ Nutr. 2002;132:2202-2207.

34. Frongillo EA. Symposium : causes and etiology of stunting. J Nutr. 1999;129:529530 .

35. Harhay MO, Horton J, Olliaro PL. Epidemiology and control of human gastrointestinal parasites in children. Expert Rev Anti Infect Ther. 2010;8(2):219-234. doi:10.1586/eri.09.119.

36. Hotez PJ, Bottazzi ME, Franco-Paredes C, et al. The neglected tropical diseases of Latin America and the Caribbean : a review of disease burden and distribution and a roadmap for control and elimination. PLoS Negl Trop Dis. 2008;2(9):1-11. doi:10.1371/journal.pntd.0000300.

37. Ezeamama AE, Friedmana JF, Acosta LP, et al. Helminth infection and cognitive impairment among filipino children. Am J Trop Med Hyg. 2005;72(5):540-548.

38. UNICEF, United Nations University, World Health Organisation. Iron Deficiency Anaemia: Assessment, Prevention, and Control; A Guide for Programme Managers. Rome: WHO. 2001: 1-132.

39. Richard SA, Mccormick BJJ, Miller MA, et al. Modeling environmental influences on child growth in the MAL-ED cohort study : opportunities and challenges. Clin Infect Dis. 2014;59(Suppl 4):255-260. doi:10.1093/cid/ciu436.

40. Nti CA, Lartey A. Effect of caregiver feeding behaviours on child nutritional status in rural Ghana. Int $J$ Consum Stud. 2007;31(October):303-309. doi:10.1111/j.14706431.2006.00553.x. 